\title{
Cx43 in mesenchymal stem cells promotes angiogenesis of the infarcted heart independent of gap junctions
}

\author{
DE-GUO WANG ${ }^{1,2^{*}}$, FENG-XIANG ZHANG ${ }^{2 *}$, MING-LONG CHEN $^{2}$, \\ HONG-JUN ZHU², BING YANG ${ }^{2}$ and KE-JIANG CAO ${ }^{2}$ \\ ${ }^{1}$ Department of Gerontology, The Yijishan Hospital of Wannan Medical College, \\ Wuhu, Anhui 241001; ${ }^{2}$ Department of Cardiology, The First Affiliated Hospital of Nanjing Medical University, \\ Nanjing, Jiangsu 210029, P.R. China
}

Received May 21, 2013; Accepted January 17, 2014

DOI: $10.3892 / \mathrm{mmr} .2014 .1923$

\begin{abstract}
Mesenchymal stem cells (MSCs) with elevated levels of connexin 43 ( $\mathrm{Cx} 43)$ have been shown to exhibit improved protection for ischemic hearts. However, it remains unclear whether $\mathrm{Cx} 43$ is involved in the paracrine actions of angiogenesis, the major mechanism of cell therapy. In the present study, an in vitro model with deprivation of oxygen and a murine myocardial infarction model with permanent ligation of the left anterior-descending (LAD) coronary artery were used to determine whether gap junctions in MSCs promote angiogenesis. It was observed that MSCs that overexpressed Cx43 (MSCs -Cx43 $_{3}$ ), improve the cardiac function of infarcted myocardium as compared with control MSCs $\left(\mathrm{MSCs}_{\text {-vector }}\right.$ ) and MSCs with $\mathrm{Cx} 43$ knocked down by small interfering RNA (MSCs ${ }_{- \text {siCx } 43_{3}}$ ), accompanied with a reduction of infarct size and an increase in the vascular density and maturity. Increased levels of representative angiogenic factors [vascular endothelial growth factor (VEGF) and basic fibroblast growth factor (bFGF)] were produced by $\mathrm{MSCs}_{-\mathrm{Cx} 43}$ compared with MSCs $_{\text {-siCx43 }}$ in vivo and in vitro. However, neither Cx43 formed gap junction specific inhibitor (Cx43 mimetic peptide) or gap junction opener (antiarrhythmic peptide) affected the production of VEGF and bFGF in MSCs under hypoxic stress. These data support the hypothesis that Cx43 in MSCs promotes angiogenesis in the infarcted heart, independent of gap junction formation.
\end{abstract}

Correspondence to: Professor De-Guo Wang, Department of Gerontology, The Yijishan Hospital of Wannan Medical College, 92 Zheshan West Road, Wuhu, Anhui 241001, P.R. China

E-mail: wangdeguo@medmail.com.cn

${ }^{*}$ Contributed equally

Key words: mesenchymal stem cells, connexins, gap junction, angiogenic cytokines, myocardial infarction

\section{Introduction}

Mesenchymal stem cells (MSCs) have been extensively investigated as potential therapeutic cells for heart failure and myocardial infarction (MI) $(1,2)$; however, their inherent weakness, including poor survival of donor cells (3) and lack of functional coupling (4) with the host tissue recount the efficacy of cell therapy. Numerous methods, including gene modification (5), cytokine stimulation (6) and hypoxic preconditioning (7), appear to augment the survival of MSCs and the upregulation of connexin 43 (Cx43).

$\mathrm{Cx} 43$ forms intracellular communication channels, known as gap junctions (GJ) and facilitates electrical coupling between cells (8). GJs are also involved in the pathophysiology of cell death in injury (9). Mitochondrial Cx43 may also regulate apoptosis $(10,11)$. Generally, Cx43 expression in MSCs is extremely low, although it may increase progressively in the cardiac microenvironment (12). Previously, studies have shown that high Cx43 expression in MSCs by gene modification or insulin-like growth factor-1 (IGF-1) preconditioning promotes cell survival, cardiomyogenesis and heart function following transplantation $(13,14)$. However, to the best of our knowledge, the role of $\mathrm{Cx} 43$ in cell therapy remains to be fully determined.

Previous studies have shown that cardiac protection of cell therapy attributes to paracrine factors released from MSCs, including angiogenic cytokines [such as vascular endothelial growth factor (VEGF) and basic fibroblast growth factor (bFGF)] and antiapoptotic factors $(15,16)$. In the current study, an in vitro model with deprivation of serum and oxygen, and a murine MI model with permanent ligation of the left anterior-descending (LAD) coronary artery were used to investigate whether $\mathrm{Cx} 43$ or gap junctions promote angiogenesis and enhance the therapeutic efficacy of MSCs.

\section{Materials and methods}

Animal care. Sprague-Dawley rats were obtained from the Experimental Animal Center of Nanjing Medical University (Nanjing, China). All experiments were approved by the Institutional Animal Care and Use Committee of Nanjing Medical University. 
Isolation and culture of bone marrow MSCs. The MSCs were isolated from the femurs of 4-week-old male Sprague-Dawley rats as described previously (3). Bone marrow was suspended in $5 \mathrm{ml}$ low glucose Dulbecco's modified Eagle's medium (DMEM) containing $100 \mathrm{U} / \mathrm{ml}$ penicillin and $100 \mu \mathrm{g} / \mathrm{ml}$ streptomycin. Mononuclear cells were recovered from the interface following centrifugation (4,000 x g, $5 \mathrm{~min}$ ) in Ficoll and were washed twice, resuspended in $10 \%$ fetal bovine serum-DMEM and plated in flasks at $1 \times 10^{6}$ cells per $100 \mathrm{~cm}^{2}$. Cultures were maintained at $37^{\circ} \mathrm{C}$ in a humidified atmosphere containing $5 \% \mathrm{CO}_{2}$. After 48 or $72 \mathrm{~h}$, non-adherent cells were discarded and the adherent cells were thoroughly washed twice with phosphate-buffered saline (PBS). Fresh complete medium was added and replaced every three or four days for $\sim 10$ days. The second passage cells were used in the in vitro and in vivo experiments.

Cx43 genetic modification of MSCs. The full-length cDNA of rat $\mathrm{Cx} 43$ was cloned into pIRES2-eGFP, a eukaryotic expression plasmid, (Clontech, Mountain View, CA, USA). The siRNA sequence 5'-CGT GGA GAT GCA CCT GAA GTT CAA GAG ACT TCA GGT GCA TCT CCA CG TTT TTT-3' was cloned into the pRNA-U6-neo-vector (GenScript Co., Piscataway, NJ, USA). Plasmids were delivered using Fugene HD transfection reagent (Roche Diagnostics $\mathrm{GmbH}$, Mannheim, Germany) according to the manufacturer's instructions. The genetically modified MSCs were termed $\mathrm{MSCs}_{\text {-vector }}$, $\mathrm{MSCs}_{-\mathrm{Cx} 43}$ and $\mathrm{MSCs}_{-\mathrm{siCx} 43}$.

Gap junction alterations between MSCs by synthetic peptides. Connexin mimetic peptides (MP) for Cx43 (SRPTEKTIFII, specific and reversible inhibitors of gap-junctional communication), antiarrhythmic peptide (AAP, $\mathrm{H}_{2} \mathrm{~N}-\mathrm{Gly}$-Ala-Gly-4 Hyp-Pro-Tyr- $\mathrm{CONH}_{2}$ ) and control peptide (CP) were synthesized by ChinaPeptides Co., Ltd. (Shanghai, China). MSCs were incubated with connexin mimetic peptides $(50 \mu \mathrm{mol})$ and antiarrhythmic peptide $(50 \mu \mathrm{mol})$ for $30 \mathrm{~min}$ to inhibit or enhance gap-junctional communication between cells and were subjected to hypoxic intervention.

Scrape loading/dye transfer (SL/DT) method. Levels of gap junctional intercellular communication (GJIC) were determined by the sSL/DT technique using a fluorescent dye, Lucifer Yellow (LY; Sigma-Aldrich, St. Louis, MO, USA) as previously described (17). Cardiomyocytes were washed thoroughly with $\mathrm{Ca}^{2+}$-free Tyrode's solution and sliced with a razor blade. A total of $0.5 \%$ LY dye was added to the cells for $5 \mathrm{~min}$ and the cells were washed three times with PBS and fixed with $4 \%$ paraformaldehyde. Cells stained with LY dye were detected by fluorescence emission with an inverted fluorescent microscope (Olympus, Tokyo, Japan) equipped with a camera.

Hypoxic model of MSCs in vitro. Hypoxic conditions were generated by incubating the cells at $37^{\circ} \mathrm{C}$ using an AnearoPack system (http://www.mgc-a.com; Mitsubishi Gas Chemical Co., Inc. Tokyo, Japan) to scavenge free oxygen. The oxygen content in the medium was $<1 \%$ within $1 \mathrm{~h}$ and maintained over the experimental time. Conditioned medium was generated as described previously (18). In brief, $90 \%$ confluent third passage MSCs were fed with serum-free high-glucose-DMEM and incubated for $8 \mathrm{~h}$ under hypoxia. The medium was then collected and subsequently assayed.

Detection of cytokine release from MSCs by enzyme-linked immunosorbent assay (ELISA). The concentrations of VEGF and bFGF were measured in the culture supernatant with ELISA kits (VEGF and bFGF; R\&D Systems, Minneapolis, MN, USA), according to the manufacturer's instructions. All samples and standards were measured in duplicate.

Myocardial infarction model and MSC transplantation. Female Sprague-Dawley rats underwent left anterior descending (LAD) coronary artery ligation to create MI, as previously described (19). Rats were anesthetized by intraperitoneal injection of pentobarbital $(50 \mathrm{mg} / \mathrm{kg}$ body weight; Roche Diagnostics $\mathrm{GmbH}$ ), endotracheally intubated and mechanically ventilated. Following thoracotomy, the LAD was ligated with a 6-0 silk suture 3-4 mm from the tip of the left atrium. Successful ligation of the LAD coronary artery was verified by visual inspection of the left ventricular apex, which showed a pale discoloration. Electrocardiography indicated an elevated S-T. Seven days following ligation, surviving animals were injected with a $30 \mu \mathrm{l}$ volume containing $5 \times 10^{5} \mathrm{MSCs}$ or PBS in three separate peri-infarct regions of the heart, using a 31-gauge needle. Two weeks following transplantation, surviving animals were used for assay.

Western blotting. The protein concentration of the samples was determined by a bicinchoninic acid protein assay (Sigma-Aldrich). Total proteins $(20 \mu \mathrm{g})$ were resolved using $14 \%$ SDS-PAGE prior to transferral to a PVDF membrane. The membrane was blocked in PBS containing $0.2 \%$ Tween-20 and 5\% skimmed milk for $2 \mathrm{~h}$ at $37^{\circ} \mathrm{C}$, and incubated overnight at $4^{\circ} \mathrm{C}$ with primary monoclonal antibodies (mouse monoclonal anti-Cx43 antibody, rabbit anti-VEGF and anti-bFGF polyclonal antibodies, and mouse antiGAPDH polyclonal antibody; Abcam, Cambridge, UK). The housekeeping protein GAPDH served as a loading control. Antibody binding was detected with polyclonal horseradish peroxidase-conjugated goat anti-mouse/rabbit IgG secondary antibodies (Chemicon, Temecula, CA, USA) and visualized using an enhanced chemiluminescence kit (Sigma-Aldrich).

Global cardiac function by direct hemodynamic evaluation. Two weeks following MI, invasive hemodynamic investigations were performed following anesthesia $(50 \mathrm{mg} / \mathrm{kg})$ and mechanical ventilation. A left ventricle catheter was inserted from the right carotid artery to the LV cavity to access intraventricular pressure. Hemodynamic data were monitored by a biological signal recording system (RM6240, Chengyi, China) to measure systolic (LVSP) and end-diastolic left ventricle pressures (LVEDP), $\pm \mathrm{dp} / \mathrm{dt}_{\max }$ and heart rate (HR).

Infarct size measurement. The hearts were removed from the rats, washed, weighed and embedded in paraffin. Sections were cut into 5- $\mu \mathrm{m}$ slices, processed and stained with Trichrome-Masson. The extent of fibrosis in the infarcted region of each heart was measured as previously described (6). The percentage of blue staining, indicative of fibrosis, was measured from the infarct area on two sections from each 
A

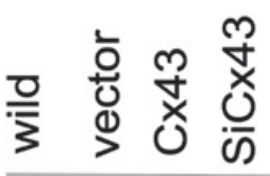

Cx43

GAPDH
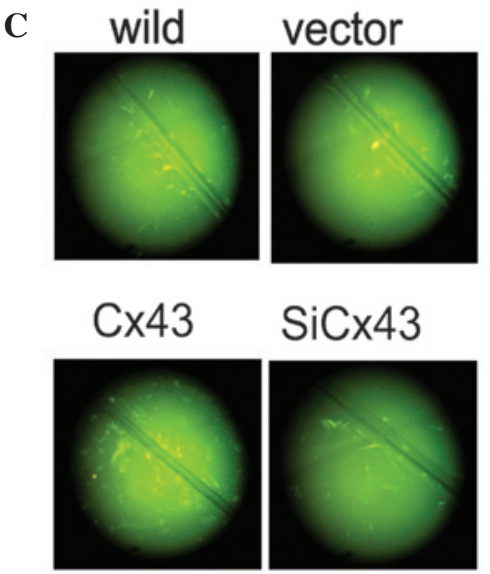

B

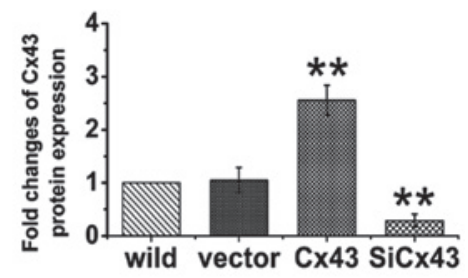

D

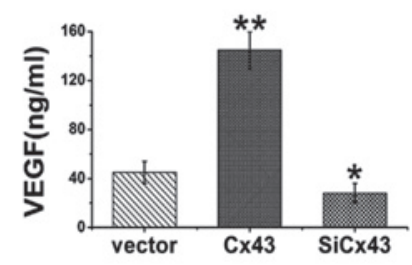

$\mathbf{E}$

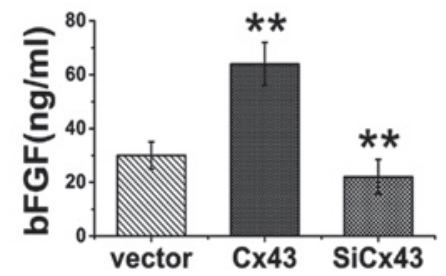

Figure 1. Cx43 genetic modification modulates production of angiogenic cytokines from MSCs. (A and B) Cx43 protein level in MSCs is upregulated by Cx43 overexpression and inhibited by siRNA. (C) Gap junctional communication between MSCs was modestly changed by Cx43 genetic modification using SL/DT. (D and E) The levels of VEGF and bFGF increased in the culture medium of Cx43 overexpressing MSCs and decreased of Cx43 knockdown MSCs after $8 \mathrm{~h}$ hypoxia by ELISA. ${ }^{*} \mathrm{P}<0.05,{ }^{* *} \mathrm{P}<0.01$ vs. vector group. Cx43, connexin 43; MSCs, mesenchymal stem cells; SL/Dt, scrape loading/dye transfer; VEGF, vascular endothelial growth factor; bFGF, basic fibroblast growth factor.

heart and averaged. The value is expressed as the ratio of Trichrome-stained fibrosis area to total infarct area.

Quantitative assessment of blood vessel density. Blood vessel density in the heart two weeks following cell therapy, was assessed as previously described (20). Briefly, cryosections (8- $\mu \mathrm{m}$ thickness) were quantified by dual fluorescent immunostaining for von Willebrand Factor-VIII (vWF-VIII) and smooth muscle actin (SMA) expression. vWF-VIII and SMA were detected with fluorescein isothiocyanate (FITC)- or rhodamine-labeled (TRITC) secondary antibodies (Roche Applied Science, Rotkreuz, Switzerland). Blood vessel density is expressed as the number of vessels per microscopic field. Blood vessel maturation was assessed by calculating the number of SMA-positive blood vessels in relation to the vWF-VIII-positive vessels.

Statistical analysis. The data are expressed as the mean \pm standard error of the mean. Two-way analysis of variance and Student's t-test were performed to analyze statistical differences in each response variable. $\mathrm{P}<0.05$ was considered to indicate a statistically significant difference.

\section{Results}

CX43 promotes the release of VEGF and bFGF from MSCs in vitro. VEGF and bFGF are the most well-studied paracrine cytokines. To illustrate the effects of $\mathrm{Cx} 43$ on the production of angiogenic cytokines, the Cx43 gene was regulated by genetic modification. Two days following transfection, Cx43 expression was increased two-fold in $\mathrm{MSCs}_{-\mathrm{Cx} 43}$ and $30 \%$ in

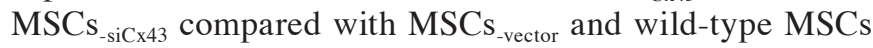
(Fig. 1A and B). SL/DT showed that LY transferred to an increased number of neighboring cells in $\mathrm{MSCs}_{-\mathrm{Cx} 43}$, but a decreased number of neighboring cells in $\mathrm{MSCs}_{-\mathrm{siCx} 43}$ (Fig. 1C) compared with $\mathrm{MSCs}_{\text {-vector. }}$ After $8 \mathrm{~h}$ of hypoxia, the levels of VEGF and bFGF were increased in MSCs $_{-\mathrm{Cx} 43}$ and decreased in $\mathrm{MSCs}_{-\mathrm{siCx} 43}$ compared with $\mathrm{MSCs}_{- \text {vector }}$ (Fig. 1D and E).

Gap junctions do not affect VEGF and bFGF secreted from MSCs in vitro. Synthesized peptides specifically recognize and reversibly bind to outer domains of proteins without entering cells (21). To confirm the role of gap junctions formed by $\mathrm{Cx} 43$ in angiogenic cytokine production, specific and reversible gap-junction closers (22) or openers (23) were used. The efficacy of the synthesized peptides in modulating gap junction was confirmed in cultured cardiomyocytes using scrape loading/LY transfer experiments (Fig. 2A). Following $8 \mathrm{~h}$ hypoxia-conditioning medium from MSCs exhibited increased VEGF and bFGF secretion. Connexin mimetic peptides, as well as the antiarrhythmic peptide, exhibited no significant effects on the production of VEGF and bFGF (Fig. 2B and 2C).

CX43 promotes the production of VEGF and bFGF following transplantation. To identify the mechanism of Cx43 in the angiogenic effect of MSCs following myocardial injury, protein of multiple paracrine factors responsible for angiogenesis from cardiac samples of the peri-infarct LV area was evaluated two weeks following transplantation $(n=4)$. Two weeks following 
A
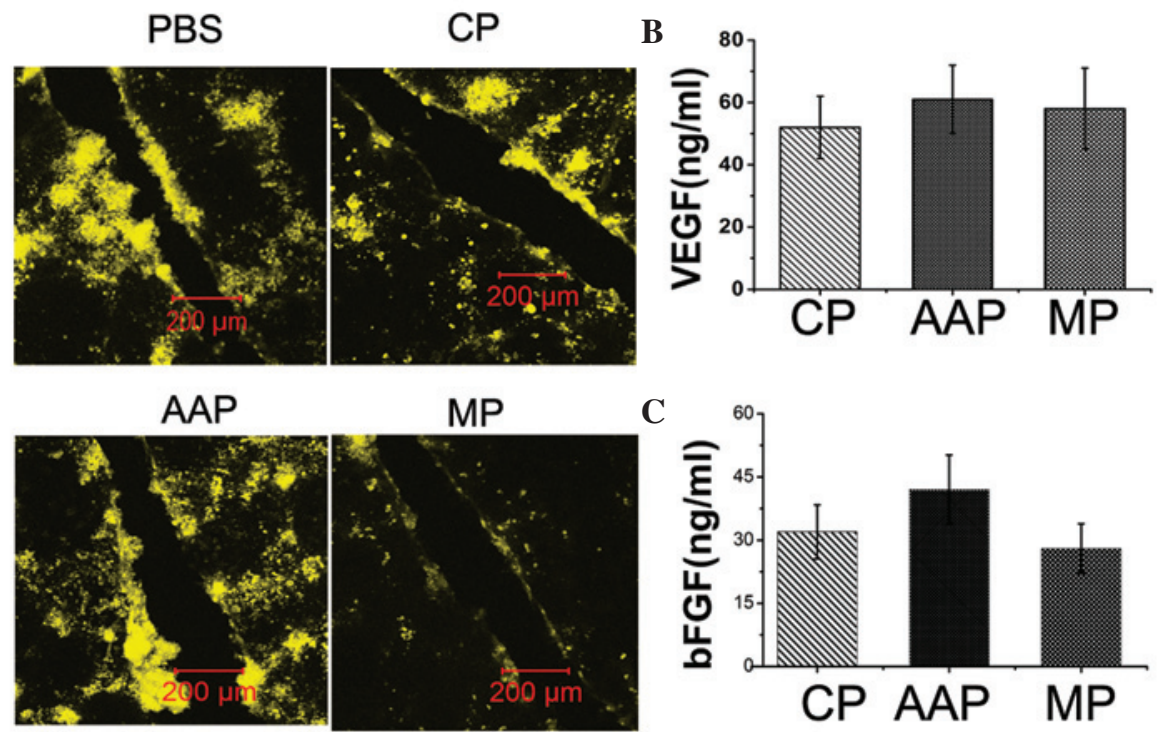

Figure 2. Gap junctional communication between MSCs has no effect on the production of angiogenic cytokines. (A) Synthesized peptides modulate gap junctional communication between cardiomyocytes by SL/DT. (B and C) Production of VEGF and bFGF from MSCs after $8 \mathrm{~h}$ hypoxia by ELISA were not affected by the gap junction inhibitor (MP) or opener (AAP). AAP, antiarrhythmic peptide; MP, connexin mimetic peptides; CP, control peptide; SL/DT, scrape loading/dye transfer; MSCs, mesenchymal stem cells; VEGF, vascular endothelial growth factor; bFGF, basic fibroblast growth factor.

A
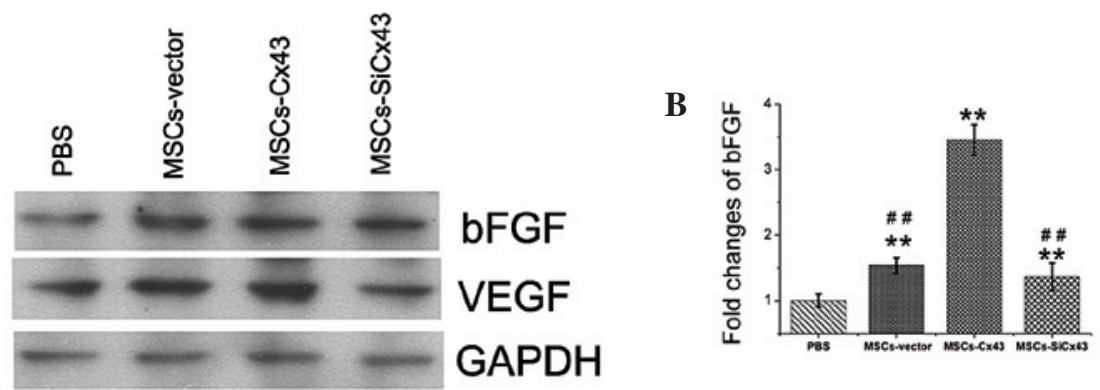

C
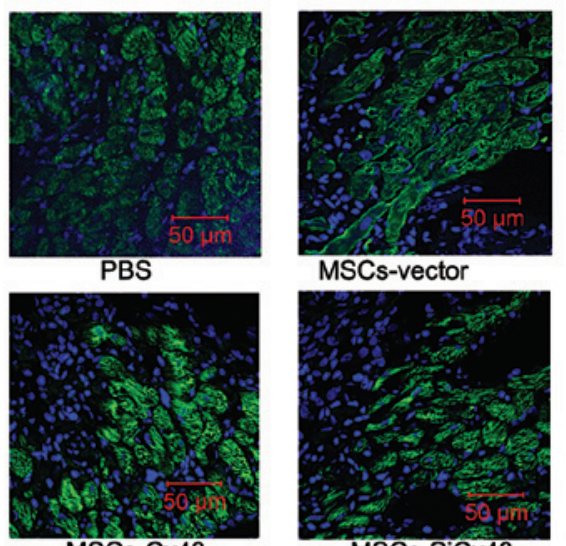

MSCs-vector

D

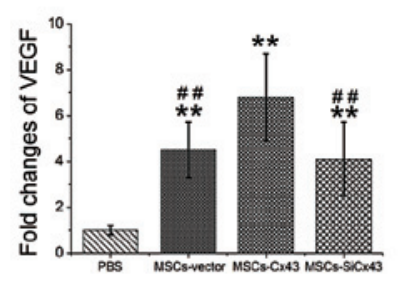

Figure 3. Transplantation of MSCs overexpressing Cx43 promotes increased levels of angiogenic cytokines in the peri-infarcted area of heart. (A) Representative images of western blots show VEGF and bFGF expression in the heart. (B) Representative images of immunofluorescent staining show VEGF expression in the infarcted border zone of the heart. (C and D) Quantitative analysis shows that protein expression of VEGF and bFGF was higher in MSCs sic $x 43_{\text {group. }}$. ${ }^{* *} \mathrm{P}<0.01$ vs. PBS group; ${ }^{\# \#} \mathrm{P}<0.01$ vs. MSCs ${ }_{-\mathrm{Cx} 43}$ group. $\mathrm{Cx} 43$, connexin 43; MSCs, mesenchymal stem cells; VEGF, vascular endothelial growth factor; bFGF, basic fibroblast growth factor; PBS, phosphate-buffered saline.

MI, immunofluororence showed VEGF expression in the infarct border zone of the heart (Fig. 3B). Western blotting showed that MSC-transplanted hearts had elevated levels of VEGF (4.5 \pm 1.2 fold) and $b F G F(1.54 \pm 0.12$ fold $)$ compared with the PBS group (Fig. 3A, C and D). There were significantly elevated
VEGF and bFGF tissue concentrations following MSCs $_{-\mathrm{Cx} 43}$ transplantation, respectively (VEGF, $6.8 \pm 1.9$ vs. $4.5 \pm 1.2$; bFGF, $3.45 \pm 0.23$ vs. $1.54 \pm 0.12 ; \mathrm{P}<0.01)$. However, no significant difference of the two paracrine factors was detected between the MSCs $_{\text {-vector }}(14.8 \pm 1.3)$ and MSCs $_{\text {-sic } \times 43}$ groups. 
A SMA vWF DAPI Merger
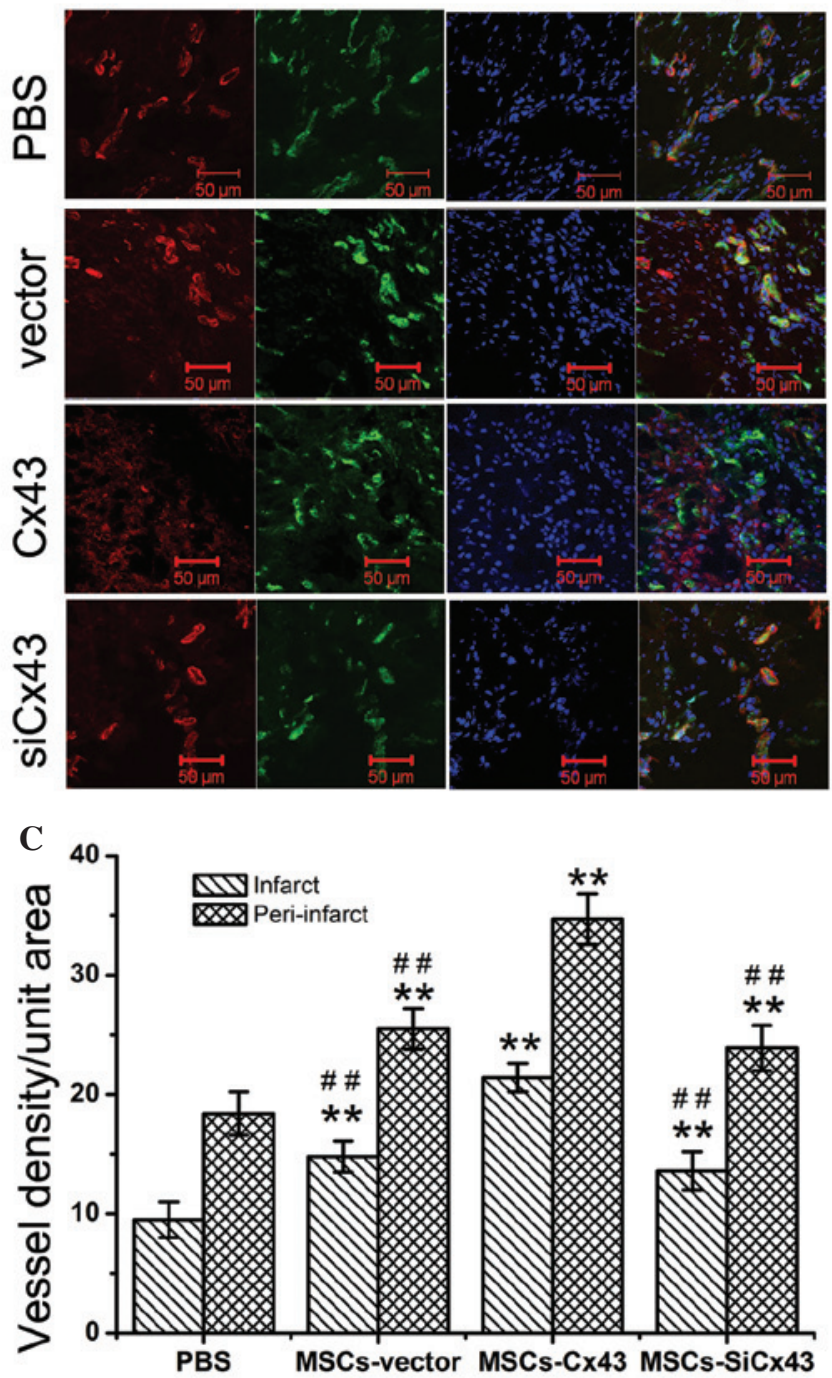

B SMA vWF DAPI Merger
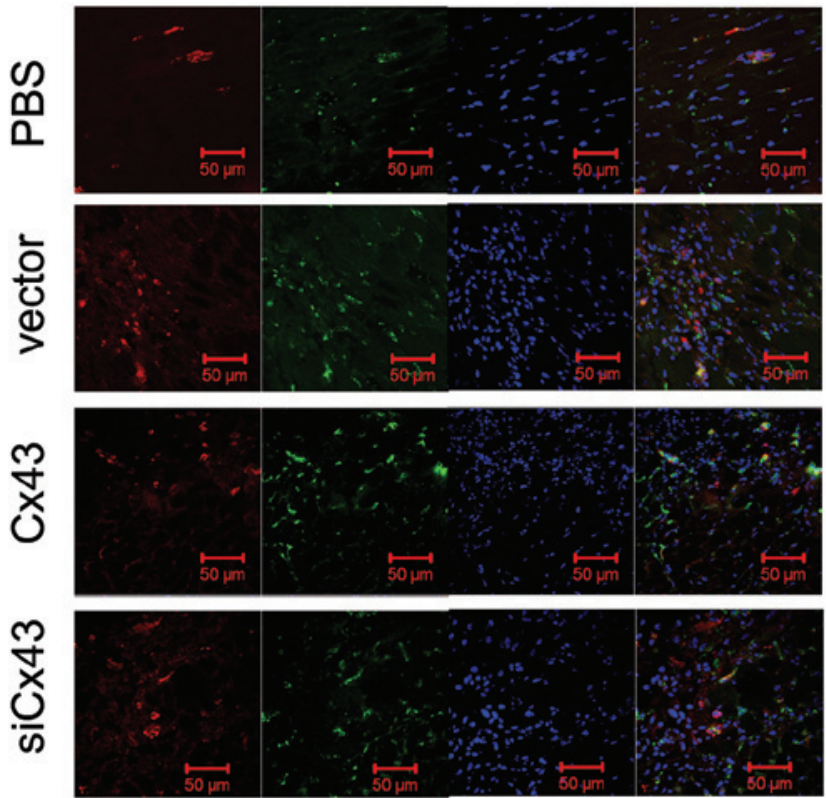

D

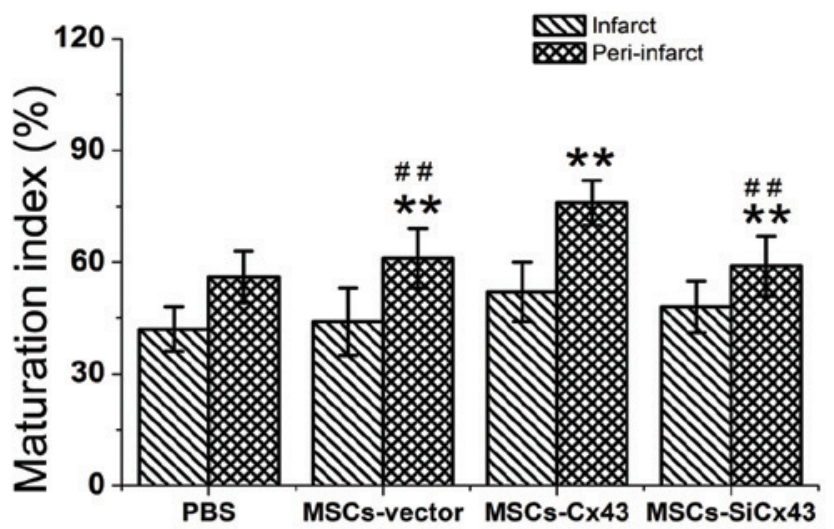

Figure 4. Neovascularization was detected by vWF (green) and SMA (red) two weeks following MSC transplantation. Representative images of immunofluorescent staining of vWF and SMA from (A) peri-infarcted and (B) infarcted areas of the heart. (C) Quantitative analysis shows blood vessel density

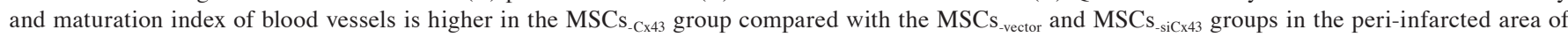
heart. No difference of vessel density and maturation index between all groups in (B) infarcted region of heart. ${ }^{* *} \mathrm{P}<0.01$, vs. the $\mathrm{PBS}$ group; ${ }^{\# \#} \mathrm{P}<0.01$, vs. the MSCs $_{-\mathrm{Cx} 43}$ group. siCx43, siRNA for Cx43; Cx43, connexin 43; vWF, vWFactor-VIII; SMA, smooth muscle actin; MSCs, mesenchymal stem cells; PBS, phosphate-buffered saline.

Cx43 promotes angiogenesis in MI in vivo. To determine the impact of $\mathrm{Cx} 43$ on angiogenesis of MSCs in the infarcted myocardium, vessel density was quantified following vWFactor-VIII (vWF) and smooth muscle actin (SMA) staining, respectively. Two weeks following MI, vessel density was higher in the cell-transplanted groups of animals compared with the PBS-injected rats (Fig. 4A and B). Blood vessel density per surface area in the infarct was significantly greater in the $\mathrm{MSCs}_{-\mathrm{Cx} 43}$ group $(21.4 \pm 1.2 ; \mathrm{P}<0.01)$ compared with the $\mathrm{MSCs}_{\text {-vector }}(14.8 \pm 1.3)$ and $\mathrm{MSCs}_{-\mathrm{siCx} 43}$ groups (13.6 \pm 1.6$)$. There was a greater vessel density in the MSCs $_{-{ }_{-443}}$ group $(34.7 \pm 2.1 ; \mathrm{P}<0.01)$ compared with the $\mathrm{MSCs}_{\text {-vector }}(25.5 \pm 1.7)$ and $\mathrm{MSCs}_{-\mathrm{siCx} 43}$ groups $(23.9 \pm 1)$ in the peri-infarcted area. However, no significant differences were identified of blood vessel density between $\mathrm{MSCs}_{\text {-vector }}(14.8 \pm 1.3)$ and $\mathrm{MSCs}_{\text {-siCx43 }}$ groups in the infarcted $(\mathrm{P}=0.154)$ and in the peri-infarcted areas $(\mathrm{P}=0.107)$ (Fig. 4C).
Double-fluorescent immunostaining for vWF and SMA expression showed the newly formed vascular structures matured to develop smooth muscle covering the infarcted and the peri-infarcted areas (Figs. 4 and 5). The maturation index (based on positivity of vessels for vWF and SMA/total number of blood vessels) was higher in the $\mathrm{MSCs}_{-\mathrm{Cx} 43}$ group $(81.1 \pm 4.1 \%)$ in the peri-infarct region compared with the $\mathrm{MSCs}_{\text {-vector }}$ group $(75.8 \pm 4.5 \%)$ and $\mathrm{MSCs}_{-\mathrm{siCx} 43}$ group $(62.4 \pm 3.5 \%)$. However, no significant differences were identified in maturation index between all groups in the infarcted areas $(43.3 \pm 4.6,45 \pm 3.8,52 \pm 5.5$ and $47 \pm 7.1 \%$, respectively; $\mathrm{P}=0.23$ ) (Fig. 4D).

Cx43-enhanced MSCs reduce infarct size and preserve cardiac hemodynamics. Myocardial infarction by LAD coronary artery ligation exhibits typical histological changes, including extensive collagen deposition (which was stained 
Table I. Hemodynamics and cardiac function (mean \pm standard error of the mean).

\begin{tabular}{|c|c|c|c|c|c|c|}
\hline Group & $\mathrm{n}$ & LVSP, $\mathrm{kPa}$ & LVEDP, kPa & $+\mathrm{dP}^{2} \mathrm{dt}_{\max },+\mathrm{kPa} / \mathrm{s}$ & $-\mathrm{dP} / \mathrm{dt}_{\max },-\mathrm{kPa} / \mathrm{s}$ & HR, bpm \\
\hline Control & 7 & $12.9 \pm 0.78$ & $0.89 \pm 0.15$ & $740 \pm 71$ & $568 \pm 64$ & $363 \pm 64$ \\
\hline PBS & 8 & $6.14 \pm 1.46^{\mathrm{b}}$ & $1.36 \pm 0.36^{\mathrm{a}}$ & $464 \pm 49^{b}$ & $376 \pm 32^{\mathrm{b}}$ & $334 \pm 31$ \\
\hline $\mathrm{MSCs}_{\text {-vector }}$ & 9 & $7.87 \pm 1.61^{\mathrm{bc}}$ & $1.06 \pm 0.09$ & $549 \pm 144^{\mathrm{b}}$ & $467 \pm 52^{\text {bd }}$ & $336 \pm 48$ \\
\hline $\mathrm{MSCs}_{-\mathrm{C} \times 43}$ & 8 & $9.79 \pm 2.42^{\mathrm{bd}}$ & $0.97 \pm 0.42^{c}$ & $599 \pm 112^{\mathrm{a}}$ & $471 \pm 46^{\mathrm{bc}}$ & $356 \pm 51$ \\
\hline $\mathrm{MSCs}_{- \text {siCx} 43_{3}}$ & 8 & $8.04 \pm 2.12^{\mathrm{bc}}$ & $1.14 \pm 0.36$ & $520 \pm 89^{b}$ & $438 \pm 56^{\mathrm{bc}}$ & $342 \pm 46$ \\
\hline
\end{tabular}

HR, heart rate; LVSP, left ventricular systolic pressure; LVEDP, left ventricular end-diastolic pressure; PBS, phosphate-buffered saline. ${ }^{a} \mathrm{P}<0.05$, vs. control group; ${ }^{\mathrm{P}}<0.01$, vs. the control group; ${ }^{\mathrm{C}} \mathrm{P}<0.05$ and ${ }^{\mathrm{d}} \mathrm{P}<0.01$, vs. the $\mathrm{PBS}$ group.
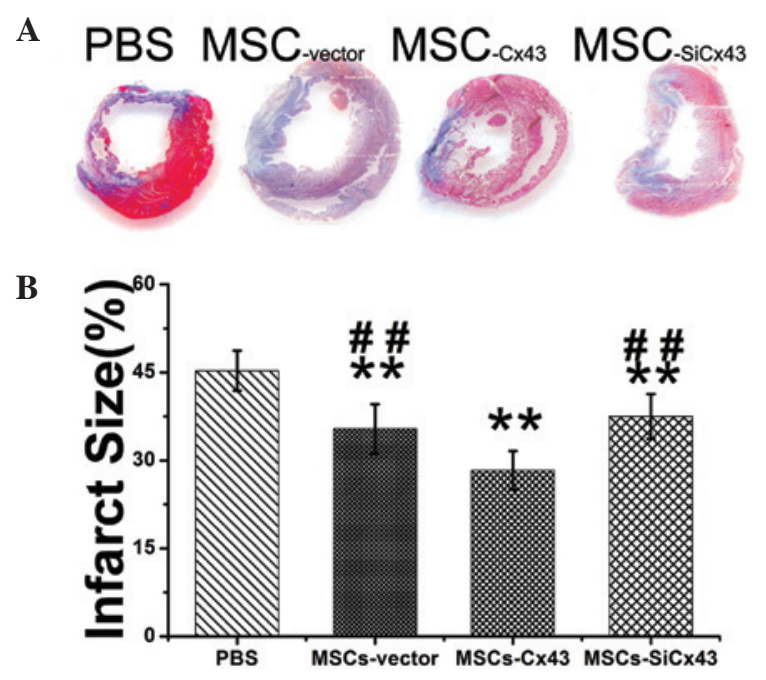

Figure 5. Transplantation of MSCs overexpressing Cx43 resulted in smaller infarct size two weeks after myocardial infarction. (A) Representative images of infarcted rat heart. (B) The area of fibrosis was significantly smaller in the infarcted heart transplanted with MSCs -Cx43 $_{3}$ than MSCs -vector $_{\text {and }}$ aSCs-sicx43. ${ }^{* *} \mathrm{P}<0.01$ vs. $\mathrm{PBS}$ group; ${ }^{\# \#} \mathrm{P}<0.01$ vs. $\mathrm{MSCs}_{-\mathrm{C} \times 43}$ group. $\mathrm{Cx} 43$, connexin 43 ; MSCs, mesenchymal stem cell; PBS, phosphate-buffered saline.

blue) and a minor viable island of myocardium stained red (Fig. 5A). Quantitative analysis showed $\sim 50 \%$ infarcted areas in the PBS group $(45.3 \pm 3.4 \%, n=5$; Fig. $5 B)$. Animals in the MSCs $_{-\mathrm{Cx} 43}$ group $(28.3 \pm 3.3 \%, \mathrm{n}=5)$ had smaller infarct size than those treated with MSCs $_{- \text {siCx } 43}(37.5 \pm 3.8 \%, n=5)$ as well as $\mathrm{MSCs}_{\text {-vector }}(35.4 \pm 4.2 \%, \mathrm{n}=5)$.

MSC-injected rats had significant hemodynamic preservation compared with PBS groups showing increased left

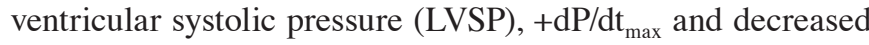
left ventricular end-diastolic pressure (LVEDP) and $-\mathrm{dP} / \mathrm{dt}_{\max }$. However, the improvement of LVSP, LVEDP and $\pm \mathrm{dP} / \mathrm{dt}_{\max }$ was greater in the $\mathrm{MSCs}_{-\mathrm{Cx} 43}$ group compared with the $\mathrm{MSCs}_{\text {-vector }}$ and MSCs $_{- \text {siCx43 }}$ groups, although the differences did not reach statistical significance (Table I).

\section{Discussion}

In the current study, three major findings were observed: i) Transplantation of $\mathrm{Cx} 43$-enriched MSCs was more effective in reducing infarct size, promoting neovascularization and preserving cardiac hemodynamics in the ischemic heart. ii) MSCs overexpressing Cx43 secreted more VEGF and bFGF in the hypoxic condition and iii) formation of gap junctional communication by $\mathrm{Cx} 43$ was not required for the production of VEGF and bFGF.

Cx43 is an essential protein in the formation of hemichannels and gap junctions responsible for electrical and mechanical coupling between cells in the myocardium (24). Previous studies demonstrated that $\mathrm{Cx} 43$ may be used to reduce proarrhythmogeny of myoblast transplantation $(25,26)$. MSCs from the bone marrow, expressing a specific amount of Cx43 (27), resulted in 4-fold reduction of arrhythmias following transplantation in ischemic heart disease in a clinical trial (28). MSCs expressing more Cx43 by growth factor (GF) stimulation exhibited improved preservation of ischemic hearts $(6,13)$. In addition, Cx43 knockdown was observed to reduce cell survival under oxygen and glucose deprivation and following transplantation into an infarcted heart (13). These studies suggest that Cx43 may contribute to the therapeutic efficacy of MSCs. Our previous study directly showed that Cx43 overexpression by genetic modification promoted survival of MSCs and cardiac function preservation in the ischemic heart (14). In the current study, transplantation of MSCs overexpressing Cx43 was observed to result in smaller infarct size and greater functional improvement. Notably, Cx43 was confirmed to promote neovascularization in infarcted hearts.

The therapeutic mechanism of MSCs on the ischemic heart has been extensively studied and repeatedly renewed from myocardial regeneration through transdifferentiation to cell fusion $(29,30)$. Currently, the paracrine actions of MSCs have been known as the major mechanism for the functional recovery of the infarcted heart (31). Therefore, Cx43 is hypothesized to affect the production of angiogenic cytokines and this may explain the improved neovascularization observed in vivo in the present study. In the current study, VEGF and bFGF concentrations were assayed in culture medium, two representative angiogenic cytokines as confirmed by previous studies $(32,33)$. The results showed that $\mathrm{Cx} 43$ genetic modification modulates VEGF and bFGF secretion from MSCs. Furthermore, VEGF was observed to be expressed in myocardial tissue of peri-infarcted areas of hearts. VEGF and bFGF protein expression increased in $\mathrm{MSCs}_{-\mathrm{Cx} 43}$ and decreased in $\mathrm{MSCs}_{-\mathrm{SiCx}_{43}}$, compared with control MSCs. Cx43 in MSCs is hypothesized to improve neovascularization in infarcted hearts through secreting more angiogenic cytokines. 
Cx43 is primarily distributed in membranes and forms gap junctions between cells for signal communication. However, a previous study observed that the majority of $\mathrm{Cx} 43$ is expressed in the cytoplasm of MSCs $(13,14)$. Lu et al $(34)$ reported that Cx43 is located in the mitochondria and involved in protecting MSCs from apoptosis. To confirm whether $\mathrm{Cx} 43$ formed gap junctions in the membrane involved in the secretion of angiogenic cytokines from MSCs, specific synthesized peptides were used to open or close the gap junctions. Since $\mathrm{Cx} 43$ mimetic peptides are not capable of directly entering cells, they selectively bind to extracellular loops of $\mathrm{Cx} 43$ and specifically inhibit gap junction functionality (21). Known as a gap junction opener, AAP has been used as an antiarrhythmic treatment. (23). Therefore, the current study differed from a study by Hahn et al, which observed that heptanol, a non-selective blocker of gap junctions, partially inhibited the antiapoptotic effects of GF treated MSCs on myocytes using co-culture with MSCs and cardiac myocytes (6). Our data showed that both AAP and MP did not affect the secretions of VEGF and bFGF from MSCs. The results suggested that overexpression of $\mathrm{Cx} 43$ in MSCs improves the production of angiogenic factors production, which is not dependent on membrane gap junctional communication.

It should be noted that this study has several limitations. Firstly, whether other connexins, e.g. Cx40 and Cx45, affect angiogenic cytokine production was not investigated. A previous study confirmed that MSCs express Cx43, Cx40 and Cx45 (27). Furthermore, antiarrhythmic peptides also open Cx45 formed gap junctions. Therefore, further study is required to determine the role of $\mathrm{Cx} 45$. Secondly, in the in vivo experiment, VEGF and bFGF arising from MSCs or myocytes themselves were not identified. Thirdly, we were unable to confirm whether the promotion of angiogenesis could be ascribed to increased cellular survival in hearts (14). Finally, neovascularization in infarcted hearts should be observed for a longer time in future studies.

In conclusion, the present study directly demonstrates that MSCs overexpressing Cx43 promote neovascularization, improve heart function and reduce infarct size. $\mathrm{Cx} 43$ is involved in the production of VEGF and bFGF from MSCs in a gap junction-independent manner. Therefore, $\mathrm{Cx} 43$ may act as a potential target for improving the therapeutic efficacy of MSC transplantation in ischemic heart disease, regardless of whether it forms gap junctions.

\section{Acknowledgements}

This study was supported by grants from the National Natural Science Foundation of China (grant nos. 30800464, 30871077 and 81200142), the National Natural Science of Anhui province (grant nos. 1208085QH156 and 1208085MH129) and the Research Foundation for Advanced Talents of Yijishan Hospital (grant no. YR201001).

\section{References}

1. Nagaya N, Kangawa K, Itoh T, et al: Transplantation of mesenchymal stem cells improves cardiac function in a rat model of dilated cardiomyopathy. Circulation 112: 1128-1135, 2005.

2. Tse HF, Thambar S, Kwong YL, et al: Prospective randomized trial of direct endomyocardial implantation of bone marrow cells for treatment of severe coronary artery diseases (PROTECT-CAD trial). Eur Heart J 28: 2998-3005, 2007.
3. Müller-Ehmsen J, Krausgrill B, Burst V, et al: Effective engraftment but poor mid-term persistence of mononuclear and mesenchymal bone marrow cells in acute and chronic rat myocardial infarction. J Mol Cell Cardiol 41: 876-884, 2006.

4. Leobon B, Garcin I, Menasche P, Vilquin JT, Audinat E and Charpak S: Myoblasts transplanted into rat infarcted myocardium are functionally isolated from their host. Proc Natl Acad Sci USA 100: 7808-7811, 2003.

5. Grauss RW, van Tuyn J, Steendijk P, et al: Forced myocardin expression enhances the therapeutic effect of human mesenchymal stem cells after transplantation in ischemic mouse hearts. Stem Cells 26: 1083-1093, 2008.

6. Hahn JY, Cho HJ, Kang HJ, et al: Pre-treatment of mesenchymal stem cells with a combination of growth factors enhances gap junction formation, cytoprotective effect on cardiomyocytes, and therapeutic efficacy for myocardial infarction. J Am Coll Cardiol 51: 933-943, 2008.

7. Rosová I, Dao M, Capoccia B, Link D and Nolta JA: Hypoxic preconditioning results in increased motility and improved therapeutic potential of human mesenchymal stem cells. Stem Cells 26: 2173-2182, 2008.

8. Contreras JE, Sánchez HA, Véliz LP, Bukauskas FF, Bennett MV and Saéz JC: Role of connexin-based gap junction channels and hemichannels in ischemia-induced cell death in nervous tissue. Brain Res Brain Res Rev 47: 290-303, 2004.

9. Yasui K, Kada K, Hojo M, et al: Cell-to-cell interaction prevents cell death in cultured neonatal rat ventricular myocytes. Cardiovasc Res 48: 68-76, 2000.

10. Giardina SF, Mikami M, Goubaeva F and Yang J: Connexin 43 confers resistance to hydrogen peroxide-mediated apoptosis. Biochem Biophys Res Commun 362: 747-752, 2007.

11. Goubaeva F, Mikami M, Giardina S, Ding B, Abe J and Yang J: Cardiac mitochondrial connexin 43 regulates apoptosis. Biochem Biophys Res Commun 352: 97-103, 2007.

12. Pijnappels DA, Schalij MJ, van Tuyn J, et al: Progressive increase in conduction velocity across human mesenchymal stem cells is mediated by enhanced electrical coupling. Cardiovasc Res 72: 282-291, 2006

13. Lu G, Haider HK, Jiang S and Ashraf M: Sca-1+ stem cell survival and engraftment in the infarcted heart: dual role for preconditioning-induced connexin-43. Circulation 119: 2587-2596, 2009.

14. Wang D, Shen W, Zhang F, Chen M, Chen H and Cao K: Connexin43 promotes survival of mesenchymal stem cells in ischemic heart. Cell Biol Int 34: 415-423, 2010.

15. Crisostomo PR, Wang Y, Markel TA, Wang M, Lahm T and Meldrum DR: Human mesenchymal stem cells stimulated by TNF-alpha, LPS, or hypoxia produce growth factors by an NF kappa B- but not JNK-dependent mechanism. Am J Physiol Cell Physiol 294: C675-C682, 2008

16. Yoon YS, Wecker A, Heyd L, et al: Clonally expanded novel multipotent stem cells from human bone marrow regenerate myocardium after myocardial infarction. J Clin Invest 115: 326-338, 2005

17. Jia G, Cheng G, Gangahar DM and Agrawal DK: Involvement of connexin 43 in angiotensin II-induce migration and proliferation of saphenous vein smooth muscle cells via the MAPK-AP-1 signaling pathway. J Mol Cell Cardiol 44: 882-890, 2008.

18. Gnecchi $\mathrm{M}, \mathrm{He} \mathrm{H}$, Noiseux $\mathrm{N}$, et al: Evidence supporting paracrine hypothesis for Akt-modified mesenchymal stem cell-mediated cardiac protection and functional improvement. FASEB J 20: 661-669, 2006.

19. Dai W, Hale SL, Martin BJ, et al: Allogeneic mesenchymal stem cell transplantation in postinfarcted rat myocardium: short- and long-term effects. Circulation 112: 214-223, 2005.

20. Jiang S, Haider H, Idris NM, Salim A and Ashraf M: Supportive interaction between cell survival signaling and angiocompetent factors enhances donor cell survival and promotes angiomyogenesis for cardiac repair. Circ Res 99: 776-784, 2006.

21. Evans WH and Leybaert L: Mimetic peptides as blockers of connexin channel-facilitated intercellular communication. Cell Commun Adhes 14: 265-273, 2007.

22. Martin PE, Wall C and Griffith TM: Effects of connexin-mimetic peptides on gap junction functionality and connexin expression in cultured vascular cells. Br J Pharmacol 144: 617-627, 2005.

23. Hagen A, Dietze A and Dhein S: Human cardiac gap-junction coupling: effects of antiarrhythmic peptide AAP10. Cardiovasc Res 83: 405-415, 2009.

24. Jansen JA, van Veen TA, de Bakker JM and van Rijen HV: Cardiac connexins and impulse propagation. J Mol Cell Cardiol 48: 76-82, 2010. 
25. Roell W, Lewalter T, Sasse P, et al: Engraftment of connexin 43-expressing cells prevents post-infarct arrhythmia. Nature 450: 819-824, 2007.

26. Abraham MR, Henrikson CA, Tung L, et al: Antiarrhythmic engineering of skeletal myoblasts for cardiac transplantation. Circ Res 97: 159-167, 2005.

27. Valiunas V, Doronin S, Valiuniene L, et al: Human mesenchymal stem cells make cardiac connexins and form functional gap junctions. J Physiol 555: 617-626, 2004.

28. Hare JM, Traverse JH, Henry TD, et al: A randomized, double-blind, placebo-controlled, dose-escalation study of intravenous adult human mesenchymal stem cells (prochymal) after acute myocardial infarction. J Am Coll Cardiol 54: 2277-2286, 2009.

29. Balsam LB, Wagers AJ, Christensen JL, Kofidis T, Weissman IL and Robbins RC: Haematopoietic stem cells adopt mature haematopoietic fates in ischaemic myocardium. Nature 428: 668-673, 2004.
30. Nygren JM, Jovinge S, Breitbach M, et al: Bone marrow-derived hematopoietic cells generate cardiomyocytes at a low frequency through cell fusion, but not transdifferentiation. Nat Med 10: 494-501, 2004.

31. Gnecchi M, He H, Liang OD, et al: Paracrine action accounts for marked protection of ischemic heart by Akt-modified mesenchymal stem cells. Nat Med 11: 367-368, 2005.

32. Grunewald M, Avraham I, Dor Y, et al: VEGF-induced adult neovascularization: recruitment, retention, and role of accessory cells. Cell 124: 175-189, 2006.

33. Langer HF, Stellos K, Steingen C, et al: Platelet derived bFGF mediates vascular integrative mechanisms of mesenchymal stem cells in vitro. J Mol Cell Cardiol 47: 315-325, 2009.

34. Lu G,Haider HKh,Porollo A and Ashraf M: Mitochondria-specific transgenic overexpression of connexin-43 simulates preconditioning-induced cytoprotection of stem cells. Cardiovasc Res 88: 277-286, 2010. 